\title{
DIFUSIÓN E INSTITUCIONALIZACIÓN DEL MOVIMIENTO DE RECUPERACIÓN DE FUENTES DE TRABAJO EN ARGENTINA
}

\author{
Ma. Amalia Gracia \\ magracia@ecosur.mx \\ El Colegio de la Frontera Sur \\ Unidad Chetumal \\ Área Sociedad, Cultura y Salud
}

\section{RESUMEN}

El artículo analiza una modalidad específica de lucha que se sitúa en el contexto de las variadas formas de conflicto que se han venido suscitando en los últimos veinte años en el país y en la región. Combinando distintas fuentes de información, explica su emergencia y difusión haciendo hincapié en la experiencia de la historia que tuvieron sus protagonistas. Esto les permitió cuestionar las transformaciones del mundo del trabajo e interpelar a distintos agentes para colocar el derecho al trabajo por encima del derecho de propiedad y hacerse con los medios de producción para gestionar las fábricas de manera más horizontal y democrática. Asimismo, se refiere a la institucionalización y aborda algunos de los desafíos de un movimiento cuyo final permanece abierto, aun cuando su instalación lo ubica como una forma posible de acción colectiva de los trabajadores cuando las empresas se encuentran en crisis.

Palabras clave: mundo del trabajo, fábricas recuperadas, cooperativas, movimientos sociales. 


\title{
DISSEMINATION AND INSTITUTIONALIZATION OF THE MOVEMENT TO RETRIEVE SOURCES OF EMPLOYMENT IN ARGENTINA
}

\begin{abstract}
This article analyzes a specific form of struggle that exists within the context of the various forms of conflict that have been emerging in the last twenty years both in Argentina and the region. Combining different sources of information, it explains the emergence and dissemination of these conflicts, emphasizing the way in which the protagonists experienced them. This enabled them to question transformations in the work sphere and address different agents in order to place the right to work over and above property rights, and gain control over the means of production so that factories could be managed in a more horizontal and democratic way. The article also addresses institutionalization, and some of the challenges of a movement that remains open-ended, even though its origin places it as a possible form of collective workers' action for times when companies go into crisis.
\end{abstract}

Key words: work sphere, retrieved factories, co-ops, social movements. 
INTRODUCCIÓN ${ }^{1}$

Este es un libro acerca de unos campesinos que no querían cambiar, por eso hicieron una revolución

Womack (1968)

Las empresas y fábricas manejadas por sus trabajadores con prescindencia de empresarios constituyen un fenómeno latinoamericano situado en el contexto de las variadas formas de conflicto que se han venido suscitando en los últimos veinte años en la región. En cuanto tales, manifiestan tendencias, señalan tensiones y abren interrogantes que pueden enriquecer los debates académicos, político-institucionales y de activistas-militantes sobre las modalidades emergentes de lucha, prácticas y acciones colectivas y sobre las posibilidades en torno a la constitución de experiencias socio-productivas alternas que conviven con y/o disputan a las formas capitalistas predominantes.

Ante la tendencia histórica de la economía capitalista de reducir el volumen de trabajadores asalariados (a partir de la incorporación de procesos productivos mecanizados y automatizados y de las cada vez más recurrentes crisis financieras internacionales) han ido emergiendo en las últimas décadas una serie de experiencias de trabajo asociativo y autogestivo para la producción y reproducción ante la incapacidad de Estado y mercado de garantizar derechos económicos, sociales, políticos, culturales y ambientales conquistados décadas atrás. Se trata de formas variadas de organizaciones protagonizadas por sujetos también diversos en sus historias, identificaciones culturales, grupos étnicos, edades, géneros.

Aquí nos referimos a un universo particular dentro de este universo más amplio, el de las denominadas «fábricas o empresas recuperadas». Asimismo, centramos nuestro análisis en el caso argentino, aunque existen procesos como estos sobre todo en Brasil, Uruguay y Venezuela y hay casos aislados en México y en muchos otros países de América Latina y el mundo. 
En Argentina el término «empresa recuperada» provino de una de las principales organizaciones que las reúnen y se refiere a las acciones y prácticas desarrolladas por los grupos de trabajadores que, apoyados por diferentes agentes y colectivos sociales, preservaron la fuente de trabajo y, paralelamente, asumieron la gestión de la producción, mayoritariamente a partir de la creación de cooperativas de trabajo.

La insistente y a veces enfática diferenciación entre nuevos y viejos actores sociales se ve profundamente desafiada por los rasgos de individuos y grupos que, ante una crisis tan profunda y generalizada como la que vivió Argentina a principios de este siglo, emprendieron acciones novedosas que terminaron cuestionando profundamente el orden fundamentalmente la propiedad de los medios de producción-, no para convertirse en otros sino para poder seguir siendo quienes eran: trabajadores con una larga tradición e historia cuya identidad estaba amenazada de muerte. ¿Cómo lograron formularse y difundirse una serie de acciones y prácticas económicas, jurídico-políticas y simbólicas? ¿Cómo entender la conformación de una forma socio-productiva que ha logrado institucionalizarse y a partir de la cual actualmente más de 200 unidades productivas experimentan cotidianamente procesos autogestionarios?

En este artículo argumentamos que para explicar la difusión e institucionalización de las recuperaciones se requiere entender cómo los protagonistas de estas experiencias vivieron, procesaron y articularon las transformaciones provocadas por dos temporalidades: por un lado, los continuos cambios en las instituciones que regulaban el mundo del trabajo en una sociedad como la argentina donde los derechos del trabajador han sido centrales como soporte de la identidad social y política; por el otro, las metamorfosis provocadas por un estado de ánimo muy particular suscitado por una crisis profunda y extendida que tuvo su punto más crítico a principios del presente siglo.

La combinación y articulación de estas temporalidades y la experiencia de la historia que 
tuvieron sus protagonistas y otros agentes sociales y políticos que los apoyaron, facilitaron la difusión de una forma socio-productiva con características particulares que plantea colocar el derecho al trabajo por encima del derecho de propiedad y en la que los trabajadores dotados de los medios de producción ejercen cotidianamente el control del proceso productivo a partir de prácticas más horizontales y equitativas. La institucionalización de este movimiento y sus desafíos actuales aún permanecen abiertos, pues, lejos de ser algo estático, la denominada «fábrica recuperada» es una forma socioproductiva dinámica y en disputa (Gracia 2011), aun cuando su perdurabilidad e instalación permiten hablar de una forma posible de acción colectiva de los trabajadores cuando las empresas o fábricas se encuentran en crisis (Gracia y Cavaliere 2007, Rebón y Salgado 2009, Programa Facultad Abierta, 2010).

Para desarrollar los argumentos utilizaré conceptos provenientes de la literatura de movimientos sociales y de los estudios del trabajo que ciertamente están estimulados e influenciados por las discusiones iniciadas hace décadas a partir de la emergencia de un nuevo modo de acumulación a nivel mundial y sus impactos en las fuerzas de trabajo, en los modos de intervención estatal y en las formas emergentes de acción colectiva.

La información primaria utilizada proviene de un amplio trabajo de investigación en terreno desarrollado en 36 unidades productivas situadas en la ciudad y provincia de Buenos Aires, República de Argentina, cuyos trabajadores protagonizaron procesos de lucha y resistencia y posteriormente se hicieron cargo de la producción. ${ }^{2}$ Casi todas las unidades productivas estudiadas pertenecen al sector industrial y la mayor parte son metalúrgicas (37.5\%) aunque también se registran fábricas alimenticias (15.6\%), ceramistas (9.4\%) y del vidrio y caucho (9.4\%). El resto se ubica en el sector textil (6.3\%), químico (6.3\%) y en los servicios de salud (6.3\%). También estudiamos una fábrica en el sector eléctrico y otra en el de muebles, así como un frigorífico. Entre las fábricas encuestadas y entrevistadas existe una gran heterogeneidad. Mientras algunas han sido líderes en su ramo -como una de ingredientes para la elaboración de helados, repostería y chocolatería que llegó a tener casi 
75\% del mercado, un frigorífico que fue uno de los más importantes del país hasta comienzos de los años noventa o una que era la mayor fabricante de sopletes del país-, otras venían perdiendo su posición y competitividad en el mercado desde hacía mucho tiempo. Finalmente, aun si al momento de la recuperación la mayoría se ubicaba dentro del universo de las pequeñas y medianas empresas, si contemplamos su evolución notamos que en su momento de máxima expansión tenían, en promedio, 216 trabajadores, es decir, no pertenecían al sector PyME.

\section{LA DIFUSIÓN DE LAS RECUPERACIONES}

Los grandes movimientos también nacen en forma de núcleos, al principio relativamente pequeños, de individuos que manifiestan una especial forma de solidaridad [...] Lo común que se encuentra en los núcleos de los movimientos que se están formando es el «estado naciente»

Alberoni (1981: 41)

La estimación del universo de fábricas recuperadas para el año 2010 es de entre 205 (Programa Facultad Abierta 2010) y 280 (OSERA 2010) con la participación de unos 10 mil trabajadores distribuidos en las distintas provincias del país, aunque con mayor concentración en la ciudad de Buenos Aires y en las provincias de Buenos Aires, Santa Fe y Córdoba, es decir, en las zonas suburbanas que habían alojado la concentración industrial más importante en décadas pasadas. En mucho menor medida, se han seguido recuperando fábricas hasta la actualidad y más recientemente los casos han ido teniendo más peso en otras provincias (estados) del país.

Las experiencias de recuperación se difundieron y conectaron en el contexto de la crisis más profunda y generalizada experimentada por la sociedad argentina en los últimos tiempos, que se extendió desde las jornadas de diciembre de 2001 hasta las elecciones y la asunción de Néstor Kirschner al gobierno, en 2003 (en cuyo intermedio se dio la renuncia 
del entonces presidente y la sucesión de otros cuatro interinos en un lapso de 10 días). Aunque desde mediados de los años noventa del siglo pasado se observan casos aislados, ${ }^{3}$ la mayoría surgió en 2002-2003.

En el contexto de la crisis, la retención de los depósitos bancarios, la falta de liquidez del sistema y la posterior declaración de estado de sitio debilitaron de tal manera los mecanismos de control social que una gran diversidad de actores, políticos y activistas de distintos niveles pudieron comenzar a problematizar, en diversos espacios cotidianos, los marcos de referencia para la acción que hasta entonces parecían incuestionables, que iban desde temáticas como la reestatización de los servicios públicos privatizados y los debates sobre la política monetaria a las discusiones sobre cómo garantizar salud y educación para todos y la necesidad de generar mayor participación ciudadana en la toma de decisiones mediante formas de democracia directa. Así se estimuló la emergencia de una solidaridad alternativa propia de un estado de lo social que, siguiendo la categoría del sociólogo italiano Francesco Alberoni, podemos nombrar como de estado naciente; esto propició que los trabajadores, apoyados por una serie de colectivos, fueran abriendo e instituyendo un campo de experimentación social de prácticas productivas, políticas, económicas, jurídicas y simbólicas que no están exentas de tensiones y conflictos (Gracia 2011).

Independientemente de su tradición intelectual, la mayoría de los teóricos que abordan problemas ligados a la acción colectiva coinciden en que, para que ésta ocurra, no es suficiente que se den las condiciones estructurales o una situación de injusticia sino que es necesario que exista un conflicto que oponga a los actores que disputan recursos materiales o simbólicos y que exista solidaridad entre ellos (Melucci 1999, Tilly 1978). Mientras que para Charles Tilly la solidaridad es una precondición para que se produzca la organización del grupo, para Alberto Melucci y para Francesco Alberoni ésta se explora, maximiza y expande durante la acción y se relaciona con la capacidad que tienen los actores de percibir los factores de tipo coyuntural que la facilitan. 
El concepto de estado naciente formulado por Alberoni hace referencia a un estado de transición de lo social constituido por una solidaridad alternativa y una exploración de las fronteras de lo posible que busca maximizar la solidaridad emergente en cierto momento histórico. Esta «experiencia fundamental» que «el grupo, en su acción teórico práctica, sintetiza con los datos históricos culturales del tiempo» (1981: 43) se puede definir en oposición al momento institucional.

«Con su iniciación, se interrumpen las características de las relaciones sociales institucionales y las formas de la vida cotidiana, y el subsistema social que ellas implican entra en un nuevo estado con propiedades particulares» (Alberoni 1981: 42). Las interraciones de este estado «no respetan la estructura de los cupos de las interacciones o de las disyunciones institucionales del estado de equilibrio» (Alberoni 1981: 71).

Lo anterior no significa que el autor identifique o reduzca estos dos estados de lo social a dicotomías como inconsciente-consciente o irracional-racional, sino más bien que busca las relaciones entre el momento de la invención social y el momento de la cotidianidad. La institucionalización tiene la doble función de extinguir el estado naciente y asegurar de otra manera su continuación, pues es la guardiana de la promesa y esperanza del estado naciente -que se concretiza justamente con ella-y, al mismo tiempo, constituye su traición.

\section{FORMACIÓN DEL GRUPO EN ESTADO NACIENTE}

Lo que se terminó llamando «fábrica recuperada» encontró su génesis en los colectivos de trabajo que laboraban en la misma empresa o fábrica. Entre algunos de los trabajadores de esos colectivos se fueron dando experiencias que surgieron cuando se resquebrajaron las fuerzas que garantizaban la cohesión y el control social en la fábrica y que fueron coadyuvando a la construcción de otro tipo de solidaridad y de vínculos.

Para poder abarcar las acciones prácticas de los trabajadores que recuperaron las fábricas 
donde habían trabajado durante años, así como otras respuestas de las clases populares de gestión colectiva del trabajo surgidas en nuestra región, es necesario ubicarlas en un periodo histórico más amplio que el de la crisis de 2001, situarlas en el marco de las mutaciones del capitalismo periférico globalizado y de la crisis, desestructuración y transformación de las instituciones y relaciones sociales que otrora regulaban el mundo del trabajo (Merklen 2005, Gracia 2011). Desde mediados de los años setenta del siglo pasado se venían dando cambios en los ejes del conflicto y en la relación laboral. Uno de los efectos más perversos del proceso de reestructuración neoliberal fue el aumento de la desocupación abierta y encubierta, así como el incremento del subempleo, la precariedad, la pobreza y la desigualdad. ${ }^{4}$ De ser una sociedad en la que, hasta los años ochenta del siglo pasado, casi 75\% de la población activa estaba involucrada en una relación salarial esa proporción se redujo a un tercio de dicha población (Merklen 2005: 79). La desocupación que comenzó a crecer en 1993- llegó casi a triplicar, desde 1995, los niveles históricamente reconocidos como normales en Argentina. En el año 2002, la tasa de desocupación trepó a 20.5\%. La fuerte escalada del desempleo y el subempleo no sólo llegó a generar problemas laborales a $35 \%$ de los trabajadores, sino que coadyuvó a mantener los salarios deprimidos.

Junto a la pérdida de puestos de trabajo (la ocupación industrial se redujo en 35\%) y la disminución del valor agregado, se observó una expansión en el volumen físico de la producción como resultado de la reconversión productiva causada por la incorporación de nuevas tecnologías, los procesos de desverticalización y terciariarización y la expansión de la jornada laboral. En el periodo 1989-2000 el volumen físico de la producción se incrementó en $21.8 \%$. Este aumento, con salarios deprimidos, significó una gran transferencia de recursos del trabajo al capital -sólo 100 empresas arrojaron 50\% de la producción-, mientras esta gran concentración tuvo como contraparte el cierre de miles de pequeñas y medianas empresas.

En este escenario, la reforma laboral realizada durante la década de los noventa del siglo pasado en materia de derecho individual y colectivo de trabajo contribuyó al 
debilitamiento, fragmentación y heterogeneización de la clase trabajadora. De esta manera, la conflictividad de carácter ofensivo que la caracterizó durante el periodo de sustitución de importaciones adquirió, sobre todo a partir de la década de los noventa, matices más defensivos que no apuntaban a la negociación de contratos colectivos y la demanda de aumentos salariales sino al reclamo por suspensiones, salarios atrasados y despidos (Fajn 2003: 21). También se desplazó el ámbito de aplicación del conflicto desde la rama de actividad hacia la empresa (Maceira y Spaltemberg 2001), lo cual puso en evidencia la heterogeneidad histórica gremial en variables como el tamaño del establecimiento, la rama de actividad y la tradición organizacional, fortaleciendo prácticas de organización y acción colectiva de base (delegados de planta) (Davolos y Perelman 2004), que fueron muy importantes en las recuperaciones.

Este horizonte laboral dista mucho del que había construido la identidad laboral de quienes recuperaron sus fábricas. Los trabajadores de las fábricas recuperadas pertenecen, en su mayoría, a la rama industrial, es decir, son los con que cuentan con una mayor experiencia organizativa, fundamentalmente sindical. En el caso de las fábricas analizadas, $77 \%$ de los trabajadores estaban sindicalizados antes de la recuperación. Se trata de un perfil de trabajador estable asalariado de la pequeña y mediana industria, con antigüedad en la empresa, perfil que les otorgaba el «orgullo» de pertenecer a la clase trabajadora cuyo estatuto y derechos habían sido construidos durante la presidencia de Juan Domingo Perón (1945-1955).

Si nos remitimos a los procesos previos a las recuperaciones, durante la década de los noventa del siglo pasado hubo un importante achicamiento de la plantilla en las fábricas estudiadas. El proceso de racionalización del empleo se dio a partir de suspensiones y despidos. En relación con esto, uno de los ex delegados de planta relata: «Cuando empezaron los conflictos por despidos venía el sindicato y decía que eso era lo más conveniente porque la empresa no podría continuar. Entonces, antes que se cierren las fábricas, que estemos todos afuera, teníamos que aceptar, [aunque] nos dolía en el alma» 
(entrevista a ex delegado de planta, mayo de 2005).

Estas palabras son indicativas de cómo la inestabilidad laboral entre los trabajadores ocupados se transformó en una angustiosa vivencia cotidiana en la que los sindicatos fueron impotentes para defender los puestos de trabajo. Los despidos de los compañeros de fábrica, el desempleo estructural, el aumento del desempleo de largo plazo y el desempleo repetitivo ejercieron una importante violencia simbólica ${ }^{5}$ que llevó a los trabajadores a aceptar suspensiones, retrasos y falta de pago y disminución del salario (no solo la pérdida de su poder adquisitivo). En las fábricas recuperadas analizadas, más de $80 \%$ experimentó reducciones salariales desde mediados de la década de los noventa, muchas veces como consecuencia de suspensiones y/o reducción del horario (29\%). Asimismo, casi todas las empresas contrajeron deudas salariales con los trabajadores.

Así, la pérdida del trabajo representa una amenaza hacia la propia identidad pues una vez que se pierde tal condición, se pasa a la categoría social de desempleado, de la cual es difícil regresar, sobre todo considerando el perfil de trabajador predominante en estas empresas, cuya edad promedio de 47 años era mayor a la población económicamente activa (PEA) del periodo.

\begin{abstract}
Yo como delegado, amigo y compañero, veía que los compañeros no se reincorporaban al sistema laboral. Veía a mis compañeros en el barrio, que la estaban pasando muy mal, que no conseguían trabajo tenían que salir a buscar changa... todavía no estaba el tema de los cartoneros, porque vinieron después, pero igual salían a buscar cualquier cosa. Para mí pasó a ser un tema muy fuerte, yo veía que el compañero que se iba despedido no tenía una solución y me asustaba mucho (entrevista a ex delegado de planta, mayo de 2005).
\end{abstract}

En este contexto, ante la amenaza de cierre o pérdida de la fuente de trabajo, las estrategias de lucha convergieron en la defensa de la fábrica y de sus maquinarias y, de acuerdo con los niveles de conflictividad, adoptaron distintas formas. En algunos casos pudieron negociar con los antiguos dueños el alquiler judicial de la planta y/o de las maquinarias, ${ }^{6}$ lo 
cual tampoco estuvo exento de conflictos e implicó que los trabajadores tuvieran que ir desarrollando una silenciosa lucha de tácticas y estrategias judiciales. En otros casos los trabajadores buscaron presionar a las autoridades y evitar que los empresarios se llevaran las maquinarias y materias primas que quedaban, estableciendo un campamento en las inmediaciones de la fábrica ${ }^{7}$ u ocupando sus instalaciones, ${ }^{8}$ con lo cual en ocasiones tuvieron que enfrentarse con las fuerzas policiales que intentaron desalojarlos.

Si bien hubo distintos tipo de situaciones, en la mayoría de los casos de recuperación las acciones de los empresarios (abandono, venta de máquinas, convocatoria de acreedores o quiebra, a menudo fraudulenta) se realizaron sin previo aviso, desentendiéndose del pago de las deudas salariales y de seguridad social contraídas en los meses anteriores. En muchos casos, ante la imposibilidad de maximizar las ganancias, los capitalistas abandonaron las empresas y en otros armaron empresas paralelas con el propósito de vaciar las primeras y transferir los bienes de producción a una nueva organización o venderlos. ${ }^{9}$ De acuerdo con muchos abogados especialistas en quiebras, dicha práctica fraudulenta ha sido habitual en los procesos de cierre y vaciamiento de las empresas en crisis en Argentina. En el caso de las empresas recuperadas por los trabajadores no sólo se destaca la cantidad que atravesó por procesos de quiebras fraudulentas, «sino también los niveles de arbitrariedad y "desprolijidad" que se produjeron en varios de los hechos dolosos» lo cual sólo puede entenderse desde «la instalación de la idea de desregulación legal y moral [...] una especie de "habitus" de la impunidad, en la que muchos empresarios despreciaban las cuestiones más elementales en el cumplimiento de la ley» (Fajn 2003: 35). Esta sensación de impunidad de la que hicieron gala empresarios, políticos, sindicalistas y otros miembros de la dirigencia argentina fue expresada claramente por uno de los trabajadores:

Ignacio se creía intocable. Se codeaba con el poder político y tenía un estatus de vida muy grande... no pensó en su empresa. Yo creo que si él hubiera dicho: "Bueno, no gasto más en mujeres, no gasto más en autos, no voy más a la timba, ${ }^{10}$ trato de salvar la empresa”, la empresa se salvaba, estoy casi seguro de eso [...] cuando nosotros empezamos la lucha él no creía que le íbamos a presentar batalla, creo que él pensó: “A éstos los aplasto como 
sea”, él no se dio cuenta lo que se venía, tenía mucha soberbia (entrevista a ex delegado de planta, mayo de 2005).

Dichos actos consumados por los capitalistas y el «habitus de impunidad» generaron fuertes sensaciones de injusticia y traición entre trabajadores que habían sido socializados en la cultura del trabajo asalariado estable y que venían tolerando desde hacía tiempo los efectos de la flexibilización laboral. En los distintos relatos se observa que en muchas de estas fábricas predominaban relaciones de carácter paternalista y que a menudo los trabajadores tenían profundamente internalizados esos vínculos de dominación.

Francesco Alberoni insiste en que, para poder explicar el carácter súbito y la profundidad de la fractura, así como la fuerza creadora del estado naciente, es necesario considerar «el peso esencial [...] del vínculo de las lealtades preexistentes y del consiguiente dramatismo de la decisión adoptada» (Alberoni 1981: 79). En unos de los casos estudiados, el incumplimiento del empresario y de su promesa de mantener la fábrica permitió reinterpretar como «engaños» los acuerdos previos de suspensiones y despidos que antes se toleraban como un mal ineludible; con ello se rompió el pacto ético entre trabajadores y empresario y se pudo ir cuestionando el tipo de vínculo que otrora tenían con él. En sus estudios, Barrington Moore ha mostrado que para que la acción colectiva tenga lugar es necesario que quienes la inician perciban que existe una violación a un acuerdo social (Moore 1989). Y justamente esa percepción fue instalándose poco a poco y de manera no lineal a partir del descubrimiento de la «mentira» y del «engaño» y del creciente riesgo de perder el empleo en un horizonte en el que predominaba la exclusión del mercado de trabajo.

Siguiendo a Alberoni, el nuevo estado en el que entraron los vínculos entre los trabajadores de cada fábrica supuso una redefinición del conflicto y de la estructuración del poder y fue habilitando las prácticas de preservación de la fuente de trabajo para su puesta en funcionamiento bajo gestión obrera A partir del análisis de las notas de campo, entrevistas 
y encuestas fuimos distinguiendo distintas propiedades del estado naciente. Entre ellas destaca la experiencia de la historia que tuvieron los sujetos estudiados, que les permitió reinterpretar el pasado y captar el presente de manera desnaturalizada, es decir, «carente de necesidades absolutas propias, y, al mismo tiempo, como dotado de una lógica propia, lógica que debe ser superada, pero que no por eso es inexistente» (Alberoni 1981: 105106).

Con la historización de pasado y presente que lograron hacer los trabajadores pudieron proyectar un nuevo futuro que puso en duda la separación tajante entre realidad y utopía (Wright 1998, citado por Santos 2011), al poder reconfigurar y apropiarse del espacio fabril. Es que lo que «se libera en el estado naciente aparece como algo que es superior a lo que oprime» pues «la liberación es esencialmente expresión, manifestación y realización de algo, plenitud de vida». Así se puede experimentar «un nuevo comienzo en el que ya no predomine la falsedad, sino la verdad» (Alberoni 1981: 98) y en el que predomine un fundamento distinto en los valores. Las palabras de un trabajador al momento de conformar la cooperativa muestran cómo se experimentaba esta «experiencia de liberación»:

Firmamos un contrato de alquiler el 20 de diciembre cuando en ese tiempo caía el gobierno de De la Rúa y se estaban matando en Plaza de Mayo. Nosotros estábamos a unas seis cuadras, ahí, firmando un contrato de alquiler que nos hacía cargo de la fábrica [...] Como que se terminaba algo y empezaba otra cosa [...] La verdad, teníamos mucho miedo de lo que nos iba a pasar pero estábamos muy contentos porque, a la vez, era una experiencia que sabíamos que era solamente de nosotros, porque ni el dueño de la empresa ni cualquier varón estarían para marcarnos el paso. Nosotros mismos nos teníamos que defender (entrevista a ex delegado de planta y presidente de la cooperativa, junio de 2005).

En sus relatos, los trabajadores hablan de un tiempo, anterior a la crisis de las empresas, en el que tenían salarios dignos, se sentían orgullosos del trabajo que realizaban e incluso muchos de ellos mantenían una buena relación con el empresario; luego viene el momento de la crisis en el que empiezan las suspensiones, la falta de pago de salarios, aguinaldo, 
vacaciones y se dejan de realizar los aportes a las obras sociales; finalmente, llega el momento en que va surgiendo la idea de armar una cooperativa y seguir ellos con la fábrica. Si bien, como expresa el trabajador en la cita, en este último periodo destacan mucho las dudas, los miedos y la incertidumbre, también sobresalen los lazos que se van logrando y la posibilidad de llevar a cabo, colectivamente, un «proyecto propio» que les permita trabajar de otra manera, con más libertad, sin tener que estar atesorando los conocimientos que antes se guardaban y que ahora pueden compartir entre ellos y otros grupos.

Es que otro rasgo característico que habilita el estado naciente es el plano de igualdad que experimentan sus integrantes; hace que las diferenciaciones precedentes se esfumen y sus miembros utilicen denominaciones igualitarias para nombrarse. Asimismo, sus miembros no sólo ponen en común sus experiencias sino también los recursos de los que disponen. Esto permite entender los procesos de igualación en los repartos y la toma de decisiones entre trabajadores con diferentes competencias laborales y recursos culturales, así como la forma en que han circulado los saberes en los nuevos grupos de trabajo conformados a partir de procesos de recuperación (Gracia 2012).

Finalmente, también se observan los cambios y las implicaciones afectivas que supone la conformación del grupo entre trabajadores que habían estado años juntos pero que descubrieron que en realidad «no se conocían» y que durante el curso de las acciones fueron reconociéndose y fortaleciendo sus lazos internos y su identidad grupal. Actuar en el estado naciente es también modificar la forma de sentir juntos, de creer, de percibir, es decir, es también actuar sobre los afectos pues «todo proceso de estado naciente es, al mismo tiempo, un proceso de pensamiento y un proceso emotivo. Se refiere a los objetos, al sí mismo y a las relaciones» (Alberoni 1981: 100). Esto también se registra en algunos a los que la «lucha se les metió en la sangre» y les permitió ahuyentar la tristeza de sentir que no podían darse una respuesta, lo cual a veces también los conectó con otros colectivos y los estimuló a desenvolver otras peleas y buscar otras conquistas mutando su percepción sobre 
sus propias experiencias sociales y políticas.

\section{DIFUSIÓN Y CONFLUENCIA DE LOS GRUPOS EN ESTADO NACIENTE}

Las leyes de expropiaciones fueron las medidas jurídicas que se terminaron generalizando y que otorgaron a los trabajadores el derecho a usar temporariamente los medios de trabajo para poner nuevamente en marcha la producción. La primera ley fue declarada por la Legislatura de la provincia de Buenos Aires en el año 2000 para la cooperativa metalúrgica «Unión y Fuerza» (ex Gip Metal). Fue promovida por Luis Caro, por entonces joven estudiante de leyes que se convertiría en uno de los impulsores de la idea de recuperación y referente de una de las principales organizaciones que nuclean a las fábricas. Ciertamente el papel de éste y otros referentes externos que fueron contribuyendo a formar las organizaciones de fábricas que impulsaron distintas medidas y gestiones con funcionarios, legisladores, jueces y empresarios ha sido fundamental para explicar la difusión e institucionalización de las recuperaciones. Sin embargo, si consideramos la experiencia de los sujetos en las recuperaciones, podemos destacar otros elementos importantes.

En uno de los primeros casos de recuperación en el que trabajamos en profundidad, la cooperativa Los Constituyentes, advertimos que, en un principio, la idea que impulsaba el doctor Caro de alquilar la planta y conformar una cooperativa les parecía irrisoria a los trabajadores. De acuerdo con sus relatos, ellos empezaron a considerar más seriamente la posibilidad luego de que fueron a visitar la cooperativa Luz y Fuerza y pudieron hablar con los trabajadores:

Fuimos unos 30-35 compañeros [...] Cuando llegamos, entramos a la fábrica y cada uno de nosotros se fue dispersando, cada uno hablaba con distintos compañeros. Luego tuvimos una reunión y ellos nos dieron aliento de que esto se podía hacer, fue muy bueno. Entonces volvimos y lo hablamos entre nosotros y nos dimos cuenta de que los mismos miedos que teníamos nosotros, ellos los habían tenido. Todo lo que nos contaban, las vivencias, eran las mismas vivencias que las de nosotros y nos dimos cuenta que ellos pudieron hacerlo, 
estaban laburando, ${ }^{11}$ era visible que estaban laburando y que estaban bien. Entonces eso nos dio la fuerza, la fuerza para poder hacerlo (entrevista a ex delegado y miembro del Consejo de Administración, mayo de 2005).

En la cita anterior se advierte que gracias a la comunicación con personas que habían tenido una experiencia similar los trabajadores pudieron apropiarse de la idea de formar la cooperativa. Si bien las capacidades propositivas y performativas de Luis Caro fueron fundamentales, el diálogo informal y espontáneo con trabajadores que habían tenido éxito en el sostenimiento de su fuente de trabajo fue lo que les permitió afrontar sus miedos y les otorgó confianza para transformarlos y emprender nuevas acciones y prácticas. Eso fue posible por el reconocimiento que se dio entre trabajadores que, al compartir estructuras de vivencia y experiencia, tenían habitus similares. Esta perspectiva de la propagación de la recuperación supone que, más allá de la importancia que ciertamente tuvieron los promotores externos que fueron surgiendo (Rebón 2007), los trabajadores constituyeron redes y subjetividades a partir del reconocimiento y la pertenencia a una historia y una cultura compartidas que fueron decisivas para la acción.

Del análisis de las notas de campo, entrevistas y encuestas se advierte que las acciones de recuperación fueron impulsadas por un grupo de trabajadores dentro de la fábrica y que algunos no participaron en ellas por no creer en su viabilidad o por requerir otro trabajo de manera inmediata. En 44\% de las fábricas encuestadas no participaron los cuadros técnicos y administrativos y en 53\% de las que participaron sólo lo hicieron algunos pocos. Los trabajadores de las actuales cooperativas manifiestan que muchas veces el personal administrativo no creyó en el proyecto pues se «sentía más afín a la patronal». Asimismo, en $68 \%$ de las unidades recuperadas estudiadas hubo algunos obreros de planta que no participaron, sobre todo porque «no creyeron en el proyecto» y «consiguieron otra cosa que les permitió mantenerse».

De los socios encuestados, 82\% afirmó haber participado en las acciones de recuperación; 
dentro de ese grupo, 63\% lo hizo desde la primera reunión y 17\% admitió no haber sido impulsor de la idea. En un primer pantallazo, el proceso de recuperación no parece relacionarse con la participación sindical previa; 22\% de quienes no participaban en el sindicato tuvieron la idea de la recuperación mientras que entre los que tomaban parte en las actividades gremiales encontramos 18\% (cuadro 1). En realidad, si controlamos el peso de esta estructura poblacional en la cual no abundan los militantes y reconsideramos estos porcentajes según la participación política previa, notamos que, entre los que tuvieron la idea de la recuperación, 30\% tuvo participación política previa y 16\% no la tuvo, lo cual señala que las experiencias previas sirvieron para proponer una salida. Asimismo, a partir de este análisis destaca el papel jugado por los delegados de planta que muchas veces se convirtieron en líderes de los procesos de recuperación.

A pesar del papel de los delegados de base, en las fábricas estudiadas no encontramos una participación activa del sindicato en estas luchas. En la mayoría los sindicatos no visualizaron la recuperación como una alternativa y se limitaron a apoyar a los trabajadores para que negociaran ante los juzgados el cobro de salarios atrasados. Entre estos casos podemos mencionar el accionar de la seccional Vicente López de la UOM, ubicada al norte del Gran Buenos Aires. A diferencia de la seccional Quilmes que sí apoyó procesos de recuperación, esta seccional ha seguido una línea gremial tradicional en consonancia con la conducción nacional del sindicato. El referente y actual secretario general de la seccional resumió la posición:

nosotros no hemos participado en la constitución de las cooperativas pero no nos hemos negado a que se constituyan. Por el contrario, en la medida que hemos podido colaborar hemos colaborado, pero es una forma que se ha organizado políticamente, a través de profesionales, profesionales de la abogacía [...] para nosotros son cooperativas de trabajo, con el nombre fábrica recuperada le han querido dar una denominación política (entrevista a la Comisión Directiva de la UOM de Vicente López, agosto de 2005). 
Cuadro 1. Participación en la recuperación según experiencia sindical previa

\begin{tabular}{|c|c|c|c|c|c|c|}
\hline \multirow[b]{2}{*}{$\begin{array}{c}\text { Intensidad de } \\
\text { participación } \\
\text { sindical previa }\end{array}$} & \multicolumn{6}{|c|}{ Intensidad de la participación en la recuperación } \\
\hline & $\begin{array}{c}\text { 1. Uno de } \\
\text { los que tuvo } \\
\text { la idea }\end{array}$ & $\begin{array}{l}\text { 2. Participó } \\
\text { desde la } \\
\text { primera } \\
\text { reunión }\end{array}$ & $\begin{array}{c}\text { 3. Participó } \\
\text { después de la } \\
\text { primera } \\
\text { reunión }\end{array}$ & $\begin{array}{l}\text { 4. Se incorporó } \\
\text { durante el 1er. } \\
\text { año a la } \\
\text { cooperativa }\end{array}$ & 5. Otro & Total \\
\hline $\begin{array}{l}\text { 1. No } \\
\text { sindicalizado }\end{array}$ & 2 & 24 & 12 & 10 & 1 & 49 \\
\hline$(\%)$ & $4.10 \%$ & $49.00 \%$ & $24.50 \%$ & $20.40 \%$ & $2.00 \%$ & $100.00 \%$ \\
\hline $\begin{array}{l}\text { 2. Sindicalizado } \\
\text { sin participación }\end{array}$ & 12 & 34 & 4 & 3 & 1 & 54 \\
\hline$(\%)$ & $22.20 \%$ & $63.00 \%$ & $7.40 \%$ & $5.60 \%$ & $1.90 \%$ & $100.00 \%$ \\
\hline $\begin{array}{l}\text { 3. Sólo votaba a } \\
\text { los delegados }\end{array}$ & 4 & 30 & 4 & 1 & 0 & 39 \\
\hline$(\%)$ & $10.30 \%$ & $76.90 \%$ & $10.30 \%$ & $2.60 \%$ & $0.00 \%$ & $100.00 \%$ \\
\hline $\begin{array}{l}\text { 4. Participaba } \\
\text { activamente }\end{array}$ & 9 & 36 & 5 & 0 & 0 & 50 \\
\hline (\%) & $18.00 \%$ & $72.00 \%$ & $10.00 \%$ & $0.00 \%$ & $0.00 \%$ & $100.00 \%$ \\
\hline $\begin{array}{l}\text { 5. Delegado o de } \\
\text { Comisión Interna }\end{array}$ & 9 & 11 & 0 & 1 & 0 & 21 \\
\hline$(\%)$ & $42.90 \%$ & $52.40 \%$ & $0.00 \%$ & $4.80 \%$ & $0.00 \%$ & $100.00 \%$ \\
\hline
\end{tabular}

Fuente: elaboración propia con base en Encuesta a Trabajadores Fábricas Recuperadas (ETFR).

De estas palabras se desprenden distintas premisas. En primer lugar, muestran la actitud que asumieron la mayoría de los sindicatos frente al fenómeno de la recuperación: «no participan» pero tampoco se «niegan a que se constituyan», lo cual indica una prolongación de las actitudes que adoptaron frente a la pérdida de puestos de trabajo y es una señal de su debilidad. Por otro lado, se cuestiona la legitimidad de los procesos por considerar que «es una forma que se ha organizado políticamente, a través de profesionales, profesionales de la 
abogacía». Es interesante notar que el cuestionamiento hacia la «fábrica recuperada» se efectúa por ser una «forma organizada políticamente», con lo cual se establece una dicotomía entre lo gremial y lo político. ¿Es que los sindicatos no constituyen una forma organizada políticamente? ¿La acción sindical no persigue resguardar derechos que parecieran estar en extinción y que fueron el resultado de luchas, protestas y movilizaciones de trabajadores? En la visión del sindicato las fábricas serían «cooperativas de trabajo», forma que ha tenido una importante tradición en Argentina y que durante la década de los noventa se multiplicó a partir del crecimiento del desempleo. Hubo algunos casos en que las cooperativas surgidas en los últimos años representaron un fraude de los propietarios que propusieron a los empleados la conformación de una cooperativa, para liberarse de ese modo del peso de impuestos y trabajadores dependientes (Palomino 2003). Con esta denominación y con la aseveración de que «se han organizado políticamente a través de profesionales de la abogacía» se insinúa un vínculo con las experiencias que supusieron un fraude hacia los trabajadores. Sin embargo, pese a dicha suspicacia, no se busca proteger a los trabajadores de estos «fraudes». Tampoco se concibe que el sindicato tenga que aportar soluciones o estrategias cuando las fábricas cierran.

Algo que destaca es el apoyo que tuvo cada grupo de parte de los vecinos, de otras fábricas y a veces de grupos del movimiento piquetero, lo cual es indicativo de la solidaridad que despertaban estas experiencias en un contexto en el que diversos grupos en estado naciente, como las asambleas barriales, también exploraban los límites de lo posible y se solidarizaban con los trabajadores. En este sentido, aun si las distintas expresiones emergentes de las jornadas de diciembre de 2001 no se lograron articular en una fuerza contra hegemónica, sí se encontraron en estas experiencias y contribuyeron al éxito de las recuperaciones. El plano de igualdad que experimentaron muchos de los que se encontraban en este estado hizo que las diferenciaciones se esfumaran y sus miembros no sólo pusieran en común sus experiencias sino también los recursos de los que disponían.

Otro rasgo sobresaliente de la información analizada es la importancia que tuvo la cercanía 
de las fábricas en la propagación de algunos de los núcleos en estado naciente. Luego de que los trabajadores de la cooperativa Los Constituyentes visitaran Unión y Fuerza -situada en el municipio de Avellaneda, sur del conurbano bonaerense- ellos mismos se convirtieron en un referente en el norte del mismo conurbano. En las entrevistas realizadas, seis cooperativas de la zona refirieron a Los Constituyentes como un «ejemplo» en los momentos en que estaban buscando soluciones ante la quiebra o el abandono del empresario.

Tanto Unión y Fuerza, Los Constituyentes y las fábricas de la zona norte cercanas a ella confluyeron en el Movimiento Nacional de Fábricas Recuperadas por sus Trabajadores (MNFRT) que se constituyó en una Organización No Gubernamental (ONG) a comienzos del año 2003. Hacia principios de 2006 reunía unas 56 cooperativas (cuadro 2), de las cuales $87 \%$ se localizaba en provincia y ciudad de Buenos Aires. Estas fábricas -que en su mayoría (31) se adhirieron al MNFRT entre los años 2002 y 2003- comparten y promueven estrategias económicas, jurídicas y político-institucionales.

El MNFRT surgió y luego se escindió del Movimiento Nacional de Empresas Recuperadas (MNER), que se había gestado a finales del año 2001 (cuadro 2), en una reunión realizada en la metalúrgica IMPA. En dicha reunión participaron distintos grupos, entre ellos la Federación de Cooperativas de Trabajo de la Provincia de Buenos Aires (FECOOTRA) (cuadro 2), conformada en 1988, que agrupaba a trabajadores con trayectoria sindical que habían creado cooperativas de trabajo durante los años ochenta para enfrentar el desempleo y por sentirse cercanos a los principios del movimiento cooperativo. A partir de este encuentro se decidió conformar un movimiento que no sólo contribuyera a consolidar las cooperativas sino que también pudiera participar «de la lucha sindical y la discusión política dentro de la clase trabajadora». La FECOOTRA, que unía la tradición sindical con la cooperativista (Palomino et al. 2010), buscó mostrar los procesos como una continuación del cooperativismo histórico, por lo cual defendió la importancia de una federación de cooperativas de trabajo y no quiso participar en la nueva organización. Sin embargo, su 
entonces abogado, Luis Caro, se integró y quedó como su representante en la provincia de Buenos Aires. En las entrevistas y charlas informales, Caro destacó su militancia social ligada al territorio en la localidad de Avellaneda, tanto en la Pastoral Social de la Iglesia Católica como en la lucha por la tierra ${ }^{12}$ y en las filas del Partido Justicialista (peronista). El otro referente del MNER, su representante en la ciudad de Buenos Aires, fue Eduardo Murúa, quien había militado en la agrupación Montoneros. ${ }^{13}$

Los líderes, grupos y organizaciones que constituyeron el MNER provenían de tradiciones y posicionamientos político-ideológicos disímiles. Sin embargo, se encontraron y gestaron un espacio que sistematizó y nombró un conjunto de prácticas con el vocablo recuperación. Nuevamente siguiendo a Alberoni, el reconocimiento no se produjo tanto «sobre la ideología sino sobre el estado del interlocutor» (Alberoni 1981: 192). Quienes confluyeron en este espacio se reconocieron porque vivían un tipo de experiencia cualitativamente diferente a la de otros y gestaron una solidaridad alternativa que permitió, sobre todo entre los años 2001 y 2002, el encuentro entre fábricas y empresas recuperadas, asambleas barriales y organizaciones de desocupados. Luego, las diferencias ideológicas y las prácticas políticas de los líderes adquirieron peso y quienes se habían reconocido como pares se distanciaron y construyeron su identidad y propuestas de manera diferencial.

Por su importancia y gravitación en el fenómeno, las dos organizaciones que resultaron de la división, el MNER y el MNFRT, han sido las que principalmente disputaron la forma que asumió la institución productiva «fábrica recuperada». Asimismo, dicha escisión marcó un punto de inflexión: al tiempo que debilitó la causa de la recuperación contribuyó a focalizar e institucionalizar la lucha. Con la nueva división del MNER en 2005, el MNFRT terminó constituyéndose en el actor más articulado pues su estrategia pragmática se concentra en la lucha jurídica y en la defensa de la legitimidad de las acciones emprendidas. 


\section{Cuadro 2. Organizaciones de unidades productivas recuperadas.}

\begin{tabular}{|c|c|c|c|c|c|}
\hline Organizaciones & $\begin{array}{c}\text { Año de } \\
\text { constitución }\end{array}$ & $\begin{array}{l}\text { Núm. }(*) \\
\text { de empresas } \\
\text { recuperadas }\end{array}$ & $\begin{array}{l}\text { Empresas referentes } \\
\text { y sectores de apoyo }\end{array}$ & $\begin{array}{l}\text { Propuestas y consignas de } \\
\text { recuperación }\end{array}$ & Principales demandas \\
\hline $\begin{array}{l}\text { FECOOTRA } \\
\text { Federación de } \\
\text { Cooperativas de Trabajo } \\
\text { de la República Argentina }\end{array}$ & 1988 & 12 & $\begin{array}{l}\text { CRISTALUX Cooperativismo } \\
\text { Federación Gráfica } \\
\text { Bonaerense }\end{array}$ & $\begin{array}{l}\text { Cooperativas que recuperan } \\
\text { empresas. }\end{array}$ & $\begin{array}{l}\text { Reforma a la Ley de } \\
\text { Cooperativas. }\end{array}$ \\
\hline $\begin{array}{l}(\text { MNER) }(* *) \\
\text { Movimiento Nacional de } \\
\text { Empresas Recuperadas }\end{array}$ & 2001 & 60 & $\begin{array}{l}\text { IMPA; UOM Quilmes; } \\
\text { Legisladores Cd. de Bs. As } \\
\text { (PSD, ARI, Izq. Unida, PS. } \\
\text { Autodeterminación y } \\
\text { Libertad); Asambleas } \\
\text { barriales; Fac. de Cs. Sociales } \\
\text { y Filosofía y Letras de la UBA }\end{array}$ & $\begin{array}{l}\text { «Ocupar, resistir, producir». } \\
\text { Alianza con otros sectores } \\
\text { movilizados }\end{array}$ & $\begin{array}{l}\text { Ley Nal. de Expropiación } \\
\text { en cesación de pagos. } \\
\text { Fondo de capital. } \\
\text { Reforma Ley de Quiebras. } \\
\text { Cesión de créditos } \\
\text { hipotecarios y prendarios. } \\
\text { Banca oficial }\end{array}$ \\
\hline $\begin{array}{l}\text { Comisión Nacional de } \\
\text { Empresas Recuperadas y } \\
\text { en Lucha }\end{array}$ & 2002 & 4 & $\begin{array}{l}\text { ZANÓN; Madres de Plaza de } \\
\text { Mayo; Asambleas barriales; } \\
\text { Sindicato de Comercio; } \\
\text { Partido de Trabajadores por el } \\
\text { Socialismo (PTS); } \\
\text { Coordinadora Alto Valle }\end{array}$ & Control obrero. & $\begin{array}{l}\text { Estatización sin cargo bajo } \\
\text { control obrero. } \\
\text { Subsidios para capital de } \\
\text { trabajo e ingreso a } \\
\text { trabajadores }\end{array}$ \\
\hline $\begin{array}{l}\text { FEENCOOTER(***) } \\
\text { Federación Nacional de } \\
\text { Cooperativas de Trabajo } \\
\text { Reconvertidas }\end{array}$ & 2002 & 14 & $\begin{array}{l}\text { Frigorífico YAGUANÉ } \\
\text { Unidad Ejecutora del Instituto } \\
\text { Nacional de Asociativismo y } \\
\text { Economía Social (INAES) }\end{array}$ & Constitución de cooperativas & Expropiación con cargo \\
\hline $\begin{array}{l}\text { MNFRT } \\
\text { Movimiento Nacional de } \\
\text { Fábricas Recuperadas por } \\
\text { sus Trabajadores }\end{array}$ & 2003 & 56 & $\begin{array}{l}\text { Unión y Fuerza; Los } \\
\text { Constituyentes; Lavalan y } \\
\text { Guelco Pastoral Social; } \\
\text { Peronismo de Avellaneda } \\
\text { UTN }\end{array}$ & $\begin{array}{l}\text { Solidaridad entre fábricas. } \\
\text { No gerenciamientos externos } \\
\text { ni créditos. } \\
\text { Interpelación jueces. } \\
\text { Competir en mercado }\end{array}$ & $\begin{array}{l}\text { Reforma a la Ley de } \\
\text { Quiebras; Ley de } \\
\text { Resolución Jurídica de la } \\
\text { Expropiaciones y Fondo } \\
\text { Especial de Recuperación } \\
\text { de Fábricas de Provincia } \\
\text { de Bs. As. }\end{array}$ \\
\hline $\begin{array}{l}\text { ANTA } \\
\text { Asociación Nacional de } \\
\text { Trabajadores } \\
\text { Autogestionados } \\
\end{array}$ & 2005 & 8 & $\begin{array}{l}\text { Central de Trabajadores } \\
\text { Argentinos (CTA) }\end{array}$ & $\begin{array}{l}\text { Derechos del trabajador } \\
\text { autogestionado }\end{array}$ & $\begin{array}{l}\text { Fondo para la Reconversión } \\
\text { Tecnológica. } \\
\text { Régimen del Trabajador } \\
\text { Autogestionado } \\
\end{array}$ \\
\hline $\begin{array}{l}\text { FACTA } \\
\text { Federación Argentina de } \\
\text { Cooperativas de } \\
\text { Trabajadores } \\
\text { Autogestionados }\end{array}$ & $\begin{array}{c}2006 \\
\text { (diciembre) }\end{array}$ & 30 & $\begin{array}{l}\text { BAUEN; MIL HOJAS } \\
\text { PAUNY (ex Zanello); } \\
\text { Peronismo de izquierda }\end{array}$ & $\begin{array}{l}\text { Acercamiento sector } \\
\text { cooperativo. } \\
\text { Economía solidaria. } \\
\text { Conformación Unión de } \\
\text { Federaciones, con ANTA y } \\
\text { FECOOTRA, entre otras }\end{array}$ & $\begin{array}{l}\text { Reforma a la Ley de } \\
\text { Cooperativas. } \\
\text { Fortalecer la producción y } \\
\text { organización }\end{array}$ \\
\hline
\end{tabular}

Fuente: Elaboración propia.

(*) Cantidad máxima que llegaron a agrupar. Se trata de un proceso muy dinámico en el que se observan escisiones, reagrupamientos y en los que también hay superposiciones.

(**) El MNER se escindió en 2003 cuando se conformó el MNFRT (a partir de esta ruptura agrupaba 44 cooperativas aproximadamente) y experimentó una nueva ruptura en 2005. Varias de las empresas que se fueron conformaron FACTA entre las que se encuentran empresas de la Red Gráfica Cooperativa.

$\left({ }^{* * *}\right)$ Esta organización prácticamente se diluyó luego de que la Unidad Ejecutora de Recuperación de Empresas en Crisis (URIEC) creada durante la presidencia de Eduardo Duhalde dejó de existir dentro del INAES. 
Ya más acá en el tiempo se observan nuevas sinergias en los agrupamientos y con otros actores (cuadro 2). Si en el primer momento se tendió a utilizar la cooperativa sólo como una herramienta jurídica disponible, ante los enormes desafíos de gestión y producción, la tradición del cooperativismo ha ido jugando un papel cada vez más importante a raíz de su acumulación y experiencia histórica. Esto se manifiesta en nuevos procesos promovidos por el sector cooperativo que buscan crear cadenas de valor, obtener ventajas comerciales y unificar posiciones para luchar conjuntamente por un marco institucional que otorgue mayores garantías al trabajo autogestivo; estos procesos se han expresado en la conformación de federaciones de segundo grado (como la Red Gráfica Bonaerense, gestada también con apoyo sindical y FACTA) (cuadro 2) e incluso uniones de tercer grado, como la Confederación Nacional de Cooperativas de Trabajo (CNCT) creada a mediados de 2009, que además muestran una articulación bastante sistemática con varios organismos gubernamentales. Además, a diferencia de los periodos previos, en la actualidad las pertenencias pueden solaparse dado que se han multiplicado las agregaciones y que, además, cada fábrica y empresa pueden converger en instancias como la «Red de Asistencia Técnica e Innovación para las Empresas Recuperadas y Cooperativas», coordinada por el Instituto Nacional de Tecnología Industrial (INTI), del que participan otros organismos públicos y Universidades e involucran 35 empresas y fábricas recuperadas.

El MNFRT ha seguido con su política de promover la solidaridad entre las fábricas que lo integran, manteniéndose al margen de estos procesos de convergencia y al mismo tiempo varias de sus cooperativas emblemáticas (como el caso de Los Constituyentes) se muestran muy críticas, distantes y en conflicto por la política impulsada, que tiende a cerrarse sobre sí misma, a no formalizar la organización y a concentrarse excesivamente en la figura de Caro. Las empresas que permanecieron en el MNER (que sigue liderado por la cooperativa IMPA) mantienen una lógica de adscripción más informal y no han avanzado, en la práctica, en procesos de complementación productiva aunque mantienen una alianza político- 
estratégica con ANTA-CTA.

\section{LA INSTITUCIONALIZACIÓN DE LA FORMA SOCIO-PRODUCTIVA «FÁBRICA RECUPERADA» EN EL CAMPO DEL TRABAJO ARGENTINO}

Las fábricas recuperadas se diferencian de las cooperativas de trabajo en tanto surgieron como un movimiento de diferentes grupos en estado naciente que fue apoyado por otros colectivos en el mismo estado, lo cual coadyuvó a que sus prácticas de gestión y organización del trabajo difirieran de un sistema cooperativo más tradicional en tanto profundizaron la horizontalidad en la distribución de responsabilidades, saberes y retiros y estimularon, con diferentes intensidades, un proceso interactivo con la comunidad al abrir la fábrica para visitas, conciertos y otras actividades sociales y culturales.

A partir de los apoyos económicos recibidos de otras fábricas, de otros agentes sociales y públicos y de las estrategias establecidas con proveedores y clientes, casi todas las fábricas estudiadas lograron insertar sus productos -que de las fábricas estudiadas $50 \%$ son de bienes de consumo intermedio- en el mercado capitalista y muy pocas venden o compran a la economía pública o a las empresas del sector de la economía social-solidaria, aunque sí se relacionan frecuentemente con otras fábricas recuperadas y, para el caso de las agrupadas en el MNFRT, han constituido un fondo de financiamiento al que recurren en caso de necesidad. Respecto a su trayectoria económica como cooperativas, observamos desarrollos diferenciales que tienen que ver con las heterogeneidades mencionadas en la introducción, aunque resalta su capacidad no sólo para preservar el empleo sino en muchos casos para ampliarlo, para mantener y conseguir nuevos clientes y para generar un ingreso que muchas veces está por encima de la media que lo establecido por los convenios colectivos para el sector o rama de actividad. Asimismo, destaca su baja tasa de mortalidad, que estaría entre 7\% (Palomino et al. 2010) y 13.6\% (Programa Facultad Abierta 2010).

El apoyo recibido desde el comienzo por distintos grupos contrasta con la intervención de agentes y funcionarios estatales de los distintos poderes y competencias jurisdiccionales 
que se produjo con posterioridad y de manera limitada y fragmentaria. Si bien la mayoría de las fábricas han recibido algún tipo de apoyo financiero del Estado, dichos apoyos no han sido demasiado significativos y las iniciativas que podrían haber resultado de mayor ayuda en términos de capital de trabajo -lo cual continúa siendo una de las mayores debilidades de las experiencias- no fueron concretadas por los gobiernos de Néstor Kirchner y luego de Cristina Fernández. Otra de las debilidades es el tema de la seguridad social de las empresas recuperadas que, al asumirse como trabajadores autónomos, no tienen los derechos del sistema unificado de seguridad social. ${ }^{14}$

Estos aspectos, junto con la incertidumbre que muchas de ellas aún tienen, ${ }^{15}$ son elocuentes de que pese a la institucionalización de sus estrategias y prácticas y a las profundas transformaciones puestas en marcha por los trabajadores, su resolución aún permanece abierta en tanto se enfrenta a marcos legales pensados, diseñados y aplicados en contextos en los que predominaban otras relaciones de trabajo.

Sin embargo, aun con sus limitaciones, los programas de política pública formulados hacia las fábricas desde la asunción del kirchnerismo en 2003 se enmarcan dentro de la transformación de los programas de empleo transitorio, asistencial y compensatorio que imperaron en los años noventa del siglo pasado y buscan contribuir con el «sostenimiento y la generación de empleo genuino», lo cual permite aseverar que los trabajadores lograron interpelar a la política pública para que los «escuchara y acompañara» en su propio territorio; ello no puede ser interpretado sólo como la iniciativa de un gobierno que logró recomponer el vendaval ocasionado por las políticas neoliberales ni como el producto de las protestas y demandas de los trabajadores sino como la cristalización de la disputa por la forma legítima que debe adoptar la fábrica recuperada en el campo del trabajo argentino.

En ese sentido, podemos decir que estos trabajadores, junto con otros agentes y movimientos, coadyuvaron a cambiar algunos de los ejes de intervención de corte asistencialista por otros que buscan recuperar la «cultura del trabajo, de la inversión» y el 
«desarrollo de los saberes y competencias construidas a lo largo de la fructífera historia productiva del país» (discurso del ministro de Trabajo, Carlos Tomada, durante el lanzamiento del Plan Más y Mejor Trabajo, octubre 2003).

La cultura del trabajo ${ }^{16}$ y su capacidad para otorgar «dignidad» no sólo han sido una de las motivaciones centrales para recuperar las fábricas (Davalos y Perelman 2004, Fernández 2004) sino también es fundamental para explicar la forma en que muchos sectores de la sociedad fueron interpelados por estas experiencias que lograron cobrar gran legitimidad social. Los trabajadores de manera repetida expresan la legitimidad de sus reglamos basados en su identidad como trabadores y en la pérdida de dignidad que significa el desempleo, lo cual fue central como argumento para obtener recursos jurídicos, económicos y políticos (programas, apoyos) que les permitieron hacerse con los medios de producción y autogestionar las empresas. A partir del análisis minucioso de las herramientas jurídicas conseguidas (fallos de los jueces y leyes de expropiación temporales) para preservar la fuente de trabajo y poder reiniciar la producción observamos cómo dichos textos rescatan la vivencia y los sentimientos de los trabajadores y resaltan la legitimidad de los reclamos frente a la ilegitimidad de una cultura empresarial que, al impedir el derecho al trabajo, justifica acciones excepcionales como la «toma» de las empresas para preservar algo sagrado, la dignidad del trabajador y su trabajo.

La capacidad estratégica y la legitimidad simbólica alcanzada por esta forma socioproductiva también se observa en uno de los discursos de la presidenta Cristina Fernández en el que comparó al país como una «gran fábrica recuperada» (INAES 2010) y en la reciente sanción de la reforma a la Ley de Quiebras que desde hace tiempo venía reclamando el MNFRT y muchas de las organizaciones, lo cual constituye un logro muy importante y es una garantía para futuras experiencias que ya no tendrán que invertir toda su energía en convencer a jueces y legisladores de que les permitan seguir trabajando, puesto que la prioridad en los procesos de quiebra se otorga a los trabajadores que, reunidos en sus dos terceras parte y organizados en cooperativa, podrán utilizar $100 \%$ de sus 
acreencias laborales para comprar marcas, maquinaria y, en algunos casos, hasta inmuebles (incluso antes de que se declare la quiebra, en el momento del Cramdowm o salvataje). Además tendrán participación en el comité de control de la quiebra pudiendo observar que no se cometan los fraudes que se manifestaron en tantos casos de empresas fallidas que luego se transformaron en recuperadas.

\section{CONSIDERACIONES FINALES}

A partir de su vivencia de las transformaciones del mundo del trabajo y buscando defender su identidad allí fincada, los trabajadores apoyados por distintos agentes y colectivos formularon prácticas económicas, políticas y culturales profundamente cuestionadoras que surgieron de manera defensiva y llegaron a ser en muchos sentidos ofensivas al reclamar la responsabilidad social de la propiedad privada e impugnar el hecho de que un grupo de empresarios que rompió el acuerdo entre capital y trabajo siguiera ostentando el control de los medios de producción.

Quienes emprendieron acciones que tenían altos grados de incertidumbre no buscaban ser otros sino reafirmar quienes eran, lo cual los caracteriza hasta hoy ya que lejos de reconocerse como empresarios o cooperativistas se autorrepresentan como trabajadores. Sin embargo, las acciones emprendidas fueron abruptas, no están exentas de problemas y suponen inmensos desafíos organizaciones y subjetivos que muchas veces generan fuertes conflictos dentro de los grupos. En este sentido, la desaparición del conflicto con el empresario abrió el espacio a otro tipo de tensiones entre las que se observan disputas por la conducción de los procesos y, sobre todo, algunas acciones individuales que atentan contra el colectivo de trabajo (Gracia 2012).

La capacidad de formulación y combinación de una serie de estrategias de confrontación, de negociación y de cooperación, diferenció a estas experiencias de otros actores emergentes de la profunda y generalizada crisis argentina -como las redes de trueque o las 
asambleas barriales-, ya que al lograr articular una forma de defenderlas y al concitar la adhesión de otros sectores, pudieron sostenerse en el tiempo. Esto constituye un aprendizaje fundamental que podría ser recuperado para otras experiencias y procesos.

A pesar del escaso apoyo sindical que recibieron, los trabajadores llevaron a cabo acciones que les permitieron preservar la fuente de trabajo, generando prácticas de invención en relación a la forma organizacional representada por los sindicatos. Como en el caso de la emergencia del movimiento de los trabajadores desocupados (movimiento piquetero), aquí se vuelve a expresar la imposibilidad de las estructuras gremiales de proponer estrategias para quienes quedan desafiliados de las relaciones salariales, al tiempo que se expresa la capacidad de los trabajadores de asumir acciones que han conllevado altos grados de incertidumbre. A diferencia de otros momentos históricos en que los sindicatos tuvieron un papel central en la ocupación de fábricas, los actuales procesos que estudiamos suponen un quiebre en el monopolio de representación ejercido por los sindicatos en la historia políticosocial argentina y plantean una serie de interrogantes y nuevas conexiones y articulaciones que es necesario seguir estudiando en procesos que son conflictivos y dinámicos. En esta dirección, si en el primer momento se tendió a utilizar la cooperativa sólo como una herramienta jurídica disponible, ante los enormes desafíos de gestión y producción, la tradición del cooperativismo ha ido jugando un papel cada vez más importante a raíz de su acumulación y experiencia histórica y tal vez esto haga que las recuperadas puedan ir profundizando sus articulaciones con otro sectores, experiencias y movimientos sociales.

Actualmente ha pasado más de una década desde que el fenómeno se difundiera y si bien tiene menos intensidad y también menos notoriedad en el país del que tuvo luego de la crisis, las primeras fábricas siguen produciendo de manera autogestiva y, mediante su aprendizaje y acumulación de experiencias dentro de la unidad productiva y en las diferentes organizaciones que las aglutinan, lograron institucionalizar una serie de estrategias jurídicas, políticas y económicas que facilitan la recuperación a los nuevos casos que han seguido surgiendo hasta el momento de escribir estas páginas. 


\section{FUENTES DE CONSULTA}

Alberoni, Francesco, 1981, Movimiento e Institución, Editora Nacional, Madrid.

Bourdieu, Pierre, 1991, El sentido práctico, Taurus, Madrid.

Davolos, Patricia y Laura Perelman, 2004, «Acción colectiva y representaciones sociales: los trabajadores de empresas recuperadas», en http://www.iisg.nl/labouragain/documents/davolos_perelman.pdf [consulta: 7 de febrero de 2005].

Programa Facultad Abierta, 2010, Las empresas recuperadas en Argentina 2010. Informe del tercer relevamiento de Empresas Recuperadas, Facultad de Filosofía y Letras de la Universidad de Buenos Aires, Secretaría de Investigación/Secretaría de Extensión Universitaria, Buenos Aires.

Fajn, Gabriel (coord.), 2003, Fábricas y empresas recuperadas. Protesta social, autogestión y rupturas en la subjetividad, Centro Cultural de la Cooperación, Ediciones del Instituto Movilizador de Fondos Cooperativos C. L, Buenos Aires.

Fernández, María Inés, 2004, «Sentidos asociados al trabajo y procesos de construcción identitaria en torno a las ocupaciones y recuperaciones de fábricas de la Ciudad de Buenos Aires: un análisis a partir de un caso en particular» en El trabajo frente al espejo. Continuidades y rupturas en los procesos de construcción identitaria de los trabajadores, compilado por Battistini, Osvaldo, Prometeo, Buenos Aires, pp. 345-365.

Gracia, María Amalia, 2012, «“Ni el patrón ni cualquier varón estaría para marcarnos el paso”. Auto-reconocimiento y relaciones de poder en prácticas socio-productivas populares» Revista Otra Economía (RILESS), v. 5, n. 9, pp. 152-172.

Gracia, María Amalia, 2011, Fábricas de resistencia y recuperación social. Experiencias de autogestión del trabajo y la producción en Argentina, El Colegio de México, México. 
Gracia, María Amalia y Sandra Cavaliere, 2007, «Repertorios en fábrica. La experiencia de recuperación fabril en Argentina, 2000-2006», Estudios Sociológicos, v. 25, n. 73, pp. 155-186.

Gramsci, Antonio, 1986-1988, Cuadernos de la cárcel, tomos I- IV, Ediciones Nueva Era, México.

Instituto Nacional de Asociativismo y Economía Social (INAES), 2010, «La Argentina es una gran Fábrica Recuperada», en http://www.inaes.gob.ar/es/noticias.asp?id=970 [consulta: 23 de octubre de 2011].

Maceira, Verónica y Ricardo Spaltemberg R., 2001, «Una aproximación al movimiento de desocupados en el marco de las transformaciones de la clase obrera en argentina», OSAL, n. 5, CLACSO, Buenos Aires, en http://bibliotecavirtual.clacso. org.ar/ar/libros/osal/osal5/analisis.pdf [consulta: 25 de enero de 2004].

Macciocchi, María Antonietta, 1974, Pour Gramsci, Éditions du Seuil, París.

Melucci, Alberto, 1999, Acción colectiva, vida cotidiana y democracia, El Colegio de México, México.

Merklen, Denis, 2005, Pobres Ciudadanos. Las clases populares en la era democrática argentina (1983-2003), Editorial Gorla, Buenos Aires.

Moore, Barrington, 1989, La injusticia: bases sociales de obediencia y la rebelión, IISUNAM, México.

Palomino, Héctor, 2003, «Las experiencias actuales de autogestión en Argentina. Entre la informalidad y la economía social», Nueva Sociedad, n. 184, Fundación Friedrich Ebert, Buenos Aires, pp. 115-128.

Palomino, Héctor, Ivanna Bleynat, Silvia Garro y Carla Giacomuzzi, 2010, «Empresas recuperadas por sus trabajadores (2002-2008). El universo, la continuidad y los cambios en el movimiento» en La nueva dinámica de las relaciones laborales en Argentina, dirigido por Héctor Palomino et al., Jorge Baudino Ediciones, Buenos Aires, pp. 27-66.

Observatorio Social sobre Empresas Recuperadas y Autogestionadas (OSERA), 2010, «Datos de la autogestión en Argentina», Informe realizado por Natalia Bauni y 
Rodrigo Salgado, con base en datos del Programa de Trabajo Autogestionado. Ministerio de Trabajo Empleo y Seguridad (Resolución MTEySS 203/04 y Resoluciones S.E. 194/04, 783/05 y 281/06), Osera, n. 4, en http://webiigg. sociales.uba.ar/empresasrecuperadas/PDF/PDF_04/datosnacion4.pdf [consulta: 1 de octubre de 2013].

Rebón, Julián, 2007, La Empresa de la Autonomía, Ediciones Picasso, Buenos Aires.

Rebón, Julián y Rodrigo Salgado, 2009, «Desafíos emergentes de las empresas recuperadas: de la imposibilidad teórica a la práctica de la posibilidad», Observatorio de la Economía Latinoamericana, n. 119, Universidad de Málaga, en http://www.eumed.net/cursecon/ecolat/ar/2009/rs.htm [consulta: 1 de enero de 2013].

Reygadas, Luis, 2002, «Producción simbólica y producción material: metáforas y conceptos en torno a la cultura del trabajo», Nueva Antropología, v. 18, n. 60, pp. 101-119.

Santos, Boaventura de Sousa, 2011, Producir para vivir. Los caminos de la producción no capitalista, Fondo de Cultura Económica, México.

Womack, John, 1968, Zapata y la revolución mexicana, Siglo XXI Editores, México.

\section{NOTAS}

\footnotetext{
${ }^{1}$ Muchas partes del artículo sintetizan argumentos esgrimidos en un libro publicado por la autora en 2011.

${ }^{2}$ Los instrumentos utilizados fueron: $a$ ) entrevistas semiestructuradas a trabajadores y otros actores sociales, políticos y otros informantes claves (39); b) observación en fábricas, reuniones y demás actividades organizadas entre ellas y $c$ ) encuestas que relevaron distintos aspectos de las empresas y los trabajadores. El trabajo de encuestas se realizó durante el mes de julio de 2005. Se obtuvieron datos a partir de la aplicación de tres cuestionarios. Dos de ellos se utilizaron para captar características de las fábricas (antes y después de la recuperación) y del proceso de recuperación, así como aspectos de organización, de producción, comerciales y jurídicos de las cooperativas (se obtuvieron 32 encuestas para uno de ellos y 18 para el otro). El tercero se utilizó para producir datos sobre la trayectoria y experiencia laboral de los trabajadores, sus funciones, participación en la recuperación y otros datos. Se levantaron 217 cuestionarios. El trabajo se realizó de manera sistemática entre marzo y septiembre de 2005 y luego -y hasta mediados de 2006- se hicieron visitas y se mantuvieron comunicaciones más esporádicas. Cabe destacar que, al menos en sus inicios, casi la totalidad de las fábricas estudiadas se adhirieron a unas de las organizaciones que las agrupan, el Movimiento Nacional de Fábricas Recuperadas por sus Trabajadores, MNFRT (véase cuadro 2). Más recientemente, en
} 
noviembre de 2012, realicé una nueva incursión en el campo, ahora enfocándome en una de las experiencias trabajadas a profundidad que fue clave para explicar la difusión de la recuperación en el municipio de Vicente López, al norte del conurbano bonaerense, y sobre algunas de las organizaciones y los agentes con los que se relaciona más cotidianamente.

${ }^{3}$ En 1996 se produjo la recuperación del Frigorífico Yaguané en el Partido (municipio) bonaerense de La Matanza y en 1998 se dieron los procesos de la metalúrgica IMPA, en ciudad de Buenos Aires y del frigorífico Ledesma, en la provincia de Santa Fe.

${ }^{4}$ Según datos del Instituto Nacional de Estadísticas (INDEC), la población bajo la línea de pobreza pasó de 28.7\% en 1995 a 57.7\% en 2002. Disponible en www.indec.gov.ar

${ }^{5}$ La violencia simbólica hace referencia a los mecanismos simbólicos (palabras, imágenes, conductas y prácticas) que motorizan el interés de los grupos dominantes, así como sus distinciones y jerarquías, convenciendo a los dominados para que asuman el orden (Bourdieu 1991: 212). Este concepto es similar a la noción de hegemonía de Gramsci que se alcanza a partir del entretejido de fuerzas sociales, políticas y culturales con valores y significados dominantes que legitiman las estructuras de desigualdad social (19861988). Para Gramsci la clase dominante ejerce su poder no sólo utilizando medios coercitivos sino también, a partir de su propia visión del mundo, una filosofía, una moral, unas costumbres, un sentido común que favorecen que los dominados reconozcan su dominación (Macciocchi 1974: 164).

${ }^{6} 26 \%$ de los trabajadores encuestados dijo haber participado de algún tipo de negociación con el empresario y $29 \%$ observó que fue a hablar con el juez.

${ }^{7} 46.4 \%$ de los trabajadores encuestados afirmó haber participado en campamentos frente a las fábricas.

${ }^{8} 65 \%$ manifestó haber «cuidado las máquinas» dentro de la fábrica.

${ }^{9}$ Observamos que los procesos de vaciamiento se hicieron a menudo en locales y bodegas ubicados junto a la fábrica. Tal el caso de una metalúrgica situada en la zona norte del GBA, en la que la patronal llevó toda la línea eléctrica de producción a un galpón junto a la planta, que incluso tiene comunicación directa con ella.

${ }^{10}$ El vocablo timba, del lunfardo, hace alusión a los juegos de azar.

${ }^{11}$ El término laburo se utiliza como sinónimo de trabajo y fue introducido por los inmigrantes italianos que llegaron a Argentina a finales del siglo XIX y principios del XX.

${ }^{12}$ Hacia mediados de los años ochenta comenzaron las ocupaciones de tierra y Luis Caro, que por entonces era delegado de la Pastoral Social y maquinista naval, organizaba cooperativas de vivienda y propiciaba expropiaciones subdividiéndoselas a quienes las ocupaban, con lo cual luego se pagaba a los dueños.

${ }^{13}$ La agrupación, de extracción peronista, surgió en el contexto de represión y proscripción política con la idea -compartida por otras agrupaciones de izquierda- de que la violencia era un método legítimo de lucha política.

${ }^{14}$ Los trabajadores no cuentan con prestaciones por desempleo, ni de asignaciones familiares ni de riesgos de trabajo. Sólo pueden contratar aseguradoras de riesgos de trabajo a título personal y, en muchos casos, no cuentan con ningún tipo de seguro debido a los costos más altos de esta opción y a los menores beneficios que representan. Asimismo, está el problema de aquellos trabajadores en edad de jubilarse cuyas empresas fallidas no cumplieron con los aportes previsionales. De acuerdo con entrevistas realizadas en noviembre de 2012, algunas experiencias están tratando de afrontar este tema a partir de una de las redes que las agrupa (FECOOTRA), aunque su concreción aún es materia difícil.

${ }^{15}$ Algunas de las leyes de expropiación (cuya naturaleza es temporal) han sido ejecutadas por el Estado y en otros casos las cooperativas han logrado comprar la fábrica y las maquinarias compensando sus deudas salariales o por su propio giro comercial. Sin embargo, la incertidumbre jurídica de muchas aún continúa. 
${ }^{16}$ Entendemos el concepto de cultura del trabajo como la «generación, actualización y transformación de formas simbólicas en la actividad laboral» (Reygadas 2002: 106), en tanto permite articular las dimensiones simbólicas con las dimensiones materiales del trabajo en un ámbito socio-histórico específico atravesado por relaciones de poder, de conflicto y negociación, y considerar el vínculo contextual de toda actividad laboral.

Fecha de recepción: 3 de enero de 2013.

Fecha de aceptación: 15 de abril de 2013. 